\title{
COVID-19 AND PATIENTS UNDERGOING PHARMACOLOGICAL TREATMENTS FOR IMMUNE-MEDIATED INFLAMMATORY DISEASES: PROTOCOL FOR A RAPID LIVING SYSTEMATIC REVIEW
}

\author{
Aline Pereira da Rocha, PhD Student ${ }^{1}$ \\ Alvaro Nagib Atallah" \\ Ana Carolina Pereira Nunes Pinto, PhD Student ${ }^{\text {II }}$ \\ César Ramos Rocha-Filho, PhD Student ${ }^{\text {IV }}$ \\ Felipe Sebastião de Assis Reis ${ }^{\mathrm{V}}$ \\ Keilla Martins Milby, PhD Student ${ }^{\mathrm{V}}$ \\ Vinicius Tassoni Civile VII \\ Nelson Carvas Junior VIII \\ Rodolfo Rodrigo Pereira Santos ${ }^{\mathrm{IX}}$ \\ Laura Jantsch Ferla ${ }^{\mathrm{X}}$ \\ Giulia Fernandes Moça Trevisani ${ }^{\mathrm{XI}}$ \\ Gabriel Sodré Ramalho XII \\ Maria Eduarda Santos Puga XIII Corresponding author \\ Virgínia Fernandes Moça Trevisani XIV
}

I MSc, Pharmacist, PhD Student, Evidence-Based Health Program, Universidade Federal de São Paulo (UNIFESP) and Volunteer Researcher, Cochrane Brazil, São Paulo (SP), Brazil. http://orcid.org/0000-0002-0863-6500

II MD, MSc, PhD. Nephrologist and Full Professor, Discipline of Emergency and Evidence-Based Medicine, Escola Paulista de Medicina (EPM), Universidade Federal de São Paulo (UNIFESP), and Director, Cochrane Brazil, São Paulo (SP), Brazil. http://orcid.org/0000-0003-0890-594X

III MSc, Physiotherapist, PhD Student., Evidence-Based Health Program, Universidade Federal de São Paulo (UNIFESP); Professor, Biological and Health Sciences Department, Universidade Federal do Amapá (AP), Brazil and Volunteer Researcher, Cochrane Brazil, São Paulo (SP), Brazil. http://orcid.org/0000-0002-1505-877X

IV MSc, Biotechnologist, PhD Student, Evidence-Based Health Program, Universidade Federal de São Paulo (UNIFESP). https://orcid.org/0000-0002-7190$\underline{0263}$

V MD, MPS, Technologies and Healthcare. Manager, Medical Practices, Beneficência Portuguesa de São Paulo. https://orcid.org/0000-0002-5728-4863

VI Nurse, PhD Student, Evidence-Based Health Program, Universidade Federal de São Paulo (UNIFESP) and Volunteer Researcher, Cochrane Brazil, São Paulo (SP), Brazil. https://orcid.org/0000-0003-0601-457X

VII MSc, Physiotherapist, PhD Student, Evidence-Based Health Program, Universidade Federal de São Paulo (UNIFESP); Assistant Professor, Physiotherapy Course, Paulista University and Volunteer Researcher, Cochrane Brazil, São Paulo (SP), Brazil. https://orcid.org/0000-0002-1718-628 VIII Physical Educator. Ibirapuera University. https://orcid.org/0000-0003-2168-8927

IX Statistician. MSc Student, Evidence-Based Health Program, Universidade Federal de São Paulo (UNIFESP). https://orcid.org/0000-0003-1540-7586

X Undergratuate Medical Student, Escola Paulista de Medicina (EPM), Universidade Federal de São Paulo (Unifesp), São Paulo (SP), Brazil https://orcid.org/0000-0002-8162-2068

XI Undergraduate Medical Student at Universidade Santo Amaro, São Paulo (SP), Brazil https://orcid.org/0000-0003-3581-3047

XII Undergratuate Medical Student, Escola Paulista de Medicina (EPM), Universidade Federal de São Paulo (Unifesp), São Paulo (SP), Brazil.https://orcid.org/0000-0001-7201-2308

XIII Librarian, Evidence-Based Health Program, Universidade Federal de São Paulo (UNIFESP).https://orcid.org/0000-0001-8470-861X

XIV MD, MSc, PhD Rheumatologist. Discipline of Emergency and Evidence-Based Medicine, Escola Paulista de Medicina (EPM), Universidade Federal de São Paulo (UNIFESP), São Paulo (SP), Brazil http://orcid.org/0000-0002-7180-6285

Research developed at the Brazilian Cochrane Center 
medRxiv preprint doi: https://doi.org/10.1101/2020.05.01.20087494; this version posted May 6, 2020. The copyright holder for this preprint (which was not certified by peer review) is the author/funder, who has granted medRxiv a license to display the preprint in perpetuity. It is made available under a CC-BY-NC 4.0 International license.

\section{ABSTRACT}

CONTEXT AND OBJECTIVE: We propose to systematically review the available evidence to evaluate if patients with immune mediated inflammatory diseases under pharmacological treatment with immunosuppressants, immunobiologics, Disease-Modifying Anti-Rheumatic Drugs (DMARD) or targeted synthetic DMARDs have better or worse outcomes when infected by severe acute respiratory syndrome coronavirus-2 (SARS-CoV-2). This study is a protocol for our rapid living systematic review. METHODS: Protocol for a rapid living systematic review methodology following the Preferred Reporting Items for Systematic Review and Meta-Analysis Protocols (PRISMA-P) guidance. To conduct the rapid systematic review, we will employ abbreviated systematic review methods, including: not performing independent screens of abstracts and not searching grey literature. As this will be a living review, it will be continuously updated.

Keywords: Immune-mediated diseases, living systematic review; COVID-19 
medRxiv preprint doi: https://doi.org/10.1101/2020.05.01.20087494; this version posted May 6, 2020. The copyright holder for this preprint (which was not certified by peer review) is the author/funder, who has granted medRxiv a license to display the preprint in perpetuity. It is made available under a CC-BY-NC 4.0 International license .

\section{INTRODUCTION}

These days, the world is facing the severe acute respiratory syndrome coronavirus-2 (SARS-CoV-2) emergency, characterized in March by the World Health Organization as a pandemic (1). It is well established in the literature that patients with compromised immune systems are more susceptible to viral infections and consequent development of severe outcomes compared with the general population. Patients with rheumatic diseases, for example, are known to present an increased infectious risk due to the disease itself and also to the iatrogenic effect of immunosuppressive agents (3). In addition, the presence of comorbidities often observed in these patients contributes to poor outcomes in viral infections (2).

In contrast to this evidence, some relevant clinical reports have described patients SARS-CoV-2 positive undergoing immunosuppressed treatment with mild symptoms and/or no severe outcomes (3). In fact, the reports have discussed that immunosuppression may protect COVID-19 patients from clinical complications.

Based on the knowledge of other viral infections, physicians and researchers hypothesize that antimalarial treatments, such as chloroquine, may prevent SARS-CoV-2 infection through endocytosis (4). Moreover, it is suggested that conventional and biological Disease-Modifying Anti-Rheumatic Drugs (DMARDs) may control pro-inflammatory cytokine expression and limit tissue damage (4). Despite the propositions, many aspects of these therapies in COVID-19 continue to be pending matters.

To address these gaps, we propose to systematically review the available evidence to answer the following question: "Do patients with immune mediated or inflammatory diseases under pharmacological treatment with immunosuppressants, immunobiologics, DMARDs or targeted synthetic DMARDs have better or worse outcomes when infected by SARS-CoV-2?" This study is a protocol for our rapid living systematic review.

\section{METHODS}

This rapid living systematic review protocol will be developed following the Preferred Reporting Items for Systematic Review and Meta-Analysis Protocols (PRISMA-P) guidance (5), and was registered in the PROSPERO "International Prospective Register of Systematic Reviews" (CRD42020179863). To conduct the rapid systematic review, we will 
medRxiv preprint doi: https://doi.org/10.1101/2020.05.01.20087494; this version posted May 6, 2020. The copyright holder for this preprint (which was not certified by peer review) is the author/funder, who has granted medRxiv a license to display the preprint in perpetuity.

It is made available under a CC-BY-NC 4.0 International license .

employ abbreviated systematic review methods, including: not performing independent screens of abstracts and not searching grey literature (6). As this is a living review, it will be continuously updated.

\section{Design}

We will perform a rapid living systematic review methodology following the recommendations proposed by the Cochrane Collaboration Handbook (7).

\section{Eligibility criteria}

\section{Types of studies}

We will include randomized controlled trials (RCT), quasi-RCTs, cohort, case-control studies, case series, and electronic health records that evaluated the effects of immunomodulatory drugs in patients with immune-mediated inflammatory diseases infected by SARS-CoV-2.

\section{Types of participants}

We will include studies with patients with confirmed diagnosis of infection of SARS-CoV-2 and immune-mediated inflammatory diseases.

\section{Type of interventions}

- Immunosuppressants (e. g. methotrexate, azathioprine, mycophenolate; cyclophosphamide);

- Immunomodulators (e.g glucocorticoids; immunoglobulins);

- Immunobiologics (e.g tocilizumab, infliximab, adalimumab, etanercept, certulizumab, rituximab, secukinumab, ustekinumab);

- DMARDs (e.g chloroquine, hydroxychloroquine, sulfasalazine);

- Targeted synthetic disease-modifying anti-rheumatic drugs (e.g. apremilast, tofacitinib, baricitinib).

\section{$\underline{\text { Outcome measures }}$}


medRxiv preprint doi: https://doi.org/10.1101/2020.05.01.20087494; this version posted May 6, 2020. The copyright holder for this preprint (which was not certified by peer review) is the author/funder, who has granted medRxiv a license to display the preprint in perpetuity. It is made available under a CC-BY-NC 4.0 International license .

- Primary outcomes

- Mortality rate;

- $\quad$ Length of hospital stay;

- $\quad$ Adverse events;

- Secondary outcomes

- Duration of invasive mechanical ventilation;

- Time to viral clearance;

- Time to clinical improvement;

- Length of Intensive Care Unit stay;

\section{Report characteristics}

We will include studies performed since November 2019. No language restrictions will be used in the selection.

\section{Data sources and searches}

We will search PubMed, Embase, Cochrane Central Register of Controlled Trials (CENTRAL), LILACS, Scopus and SciELO using relevant descriptors and synonyms, adapting the search to the specifications of each database to identify published, ongoing, and unpublished studies. We will also search the following COVID-19 specific databases: Epistemonikos COVID-19 L.OVE platform; ClinicalTrials.gov; The World Health Organization International Clinical Trials Registry Platform (WHO ICTRP). Finally, we will search the lists of references of the included studies. No language restrictions will be used in the selection.

\section{Search strategy}

We will use the terms related to the problem of interest, the intervention and the filter the date of publication. The search strategy in Medline via Pubmed is shown in Table 1. 
medRxiv preprint doi: https://doi.org/10.1101/2020.05.01.20087494; this version posted May 6, 2020. The copyright holder for this preprint

(which was not certified by peer review) is the author/funder, who has granted medRxiv a license to display the preprint in perpetuity.

It is made available under a CC-BY-NC 4.0 International license .

Table 1. Systematic review Search Strategy

\begin{tabular}{lll}
\hline Number & Combiners & Terms \\
\hline $\mathbf{1}$ & Problem & (("Coronavirus"[Mesh]) OR ("Coronaviridae"[Mesh]) OR ("Coronavirus Infections"[Mesh]) OR coronavirinae \\
of & OR ("COVID-19" [Supplementary Concept]) OR COVID OR ("severe acute respiratory syndrome \\
& interest & coronavirus 2"[Supplementary Concept]) OR SARS-CoV-2 OR ("betacoronavirus"[MeSH Terms]) OR \\
& Coronaviruses OR 2019-nCoV OR nCoV OR COVID19 OR (Corona virus)
\end{tabular}

$2 \quad$ Intervention

("Interleukin-6"[Mesh]) OR interleukin 6 OR "IL 6" OR IL-6 OR IL6 OR ("tocilizumab" [Supplementary Concept]) OR Tocilizum* OR altizumab OR actemra OR RHPM-1 OR RG-1569 OR R-1569 OR MSB11456 OR MSB-11456 OR (monoclonal antibody, MRA) OR (RO-4877533) OR roactemra OR anti $\square$ IL $\square 6$ OR anti $\square$ interleukin $\square 6$ OR ("siltuximab" [Supplementary Concept]) OR CLLB8 OR (cClB8 monoclonal antibody) OR Sylvant OR CNTO-328 OR (CNTO 328 monoclonal antibody) OR (monoclonal antibody CNTO328) OR ("sarilumab" [Supplementary Concept]) OR SAR-153191 OR SAR153191 OR Kevzara OR REGN-88 OR REGN88 OR ("olokizumab" [Supplementary Concept]) OR CDP-6038 OR CDP6038 OR elsilimomab OR BMS945429 OR ALD518 OR ("sirukumab" [Supplementary Concept]) OR (CNTO 136) OR CNTO-136 OR CPSI-2364 OR ALX-0061 OR ("clazakizumab" [Supplementary Concept]) OR ALD-518 OR ALD518 OR BMS-945429 OR ("olokizumab" [Supplementary Concept]) OR CDP-6038 OR CDP6038 OR ("sarilumab" [Supplementary Concept]) OR SAR-153191 OR SAR153191 OR Kevzara OR REGN-88 OR REGN88 OR ("sirukumab" [Supplementary Concept]) OR ARGX-109 OR FE301 OR FM101 OR ("Tumor Necrosis Factor-alpha"[Mesh]) OR TNF OR TNF-alpha OR TNF-a OR Anti-TNF OR ("Infliximab"[Mesh]) OR (Monoclonal Antibody cA2) OR (MAb cA2) OR Infliximab-abda OR Renflexis OR Infliximab-dyyb OR Inflectra OR Remicade OR ("Etanercept"[Mesh]) OR (TNFR-Fc Fusion Protein) OR (TNR 001) OR (TNT Receptor Fusion Protein) OR TNTR-Fc OR TNR-001 OR TNR001 OR Etanercept-szzs OR (TNF Receptor Type II-IgG Fusion Protein) OR (TNF Receptor Type II IgG Fusion Protein) OR Erelzi OR (Recombinant Human Dimeric TNF Receptor Type II-IgG Fusion Protein) OR (Recombinant Human Dimeric TNF Receptor Type II IgG Fusion Protein) OR Enbrel OR ("Certolizumab Pegol"[Mesh]) OR Certolizumab OR Cimzia OR CDP870 OR (CDP 870) OR ("golimumab" [Supplementary Concept]) OR CNTO-148 OR (CNTO 148) OR Simponi OR ("Adalimumab"[Mesh]) OR Humira OR Adalimumab-adbm OR Amjevita OR Adalimumab-atto OR Cyltezo OR (D2E7 Antibody) OR (Antibody, D2E7) OR ("Interleukin1"[Mesh]) OR IL-1 OR IL-1RA OR "IL 1" OR ("canakinumab" [Supplementary Concept]) OR ilaris OR ACZ885 OR ACZ885 OR anti-IL-1 OR ("rilonacept" [Supplementary Concept]) OR ACZ885 OR anakinra OR ("Interleukin-5"[Mesh]) OR Anti-IL-5: ("mepolizumab" [Supplementary Concept]) OR Bosatria OR SB240563 OR SB240563 OR Nucala OR ("Interleukin-12"[Mesh]) OR IL-12 OR ("Ustekinumab"[Mesh]) OR Stelara OR (CNTO 1275) OR CNTO-1275 OR ("Interleukin-23"[Mesh]) OR IL-23 OR "IL 23" OR ("briakinumab" [Supplementary Concept]) OR A-796874.0 OR BSF-415977 OR (BSF 415977) OR WAY165772 OR LU-415977 OR (LU 415977) OR J-695 OR J695 OR ABT-874 OR (ABT-874 antibody, human) OR Anti-C5 OR ("eculizumab" [Supplementary Concept]) OR Alexion OR Soliris OR 5G1.1 OT (H5G1.1VHC+H5G1.1VLC) OR H5G1.1 OR H5G1-1 OR H5G11 OR ("Abatacept"[Mesh]) OR LEA29Y OR BMS224818 OR BMS-224818 OR (BMS 224818) OR Belatacept OR (BMS 188667) OR (BMS-188667) OR CTLA-4-Ig OR (Cytotoxic T Lymphocyte-Associated Antigen 4-Immunoglobulin) OR (Cytotoxic T Lymphocyte Associated Antigen 4 Immunoglobulin) OR CTLA4-Ig OR (CTLA4-Ig Immunoconjugate) OR (CTLA4 Ig Immunoconjugate) OR (Immunoconjugate, CTLA4-Ig) OR CTLA4-Fc OR Nulojix OR ("Rituximab"[Mesh]) OR (CD20 Antibody) OR (Rituximab CD20 Antibody) OR Mabthera OR (IDEC-C2B8 Antibody) OR (IDEC C2B8 Antibody) OR (IDEC-C2B8) OR (IDEC C2B8) OR GP2013 OR Rituxan OR ("Antigens, CD20"[Mesh]) OR (CD20 Antigen) OR (CD20 Antigens) OR ("belimumab" [Supplementary Concept]) OR (BEL-114333) OR BEL114333 OR HGS-1006 OR HGS1006 OR LymphoStat-B OR GSK1550188 OR GSK1550188 OR Benlysta OR ("secukinumab" [Supplementary Concept]) OR ("Interleukin17"[Mesh]) OR IL-17A OR IL-17 OR "IL 17" OR ("ixekizumab" [Supplementary Concept]) OR ("brodalumab" [Supplementary Concept]) OR ("guselkumab" [Supplementary Concept]) OR ("tildrakizumab" [Supplementary Concept]) OR ("risankizumab" [Supplementary Concept]) OR ("apremilast" [Supplementary Concept]) OR Otezla OR (CC 10004) OR CC10004 OR CC-10004 OR ("tofacitinib" [Supplementary Concept]) OR tasocitinib OR (tofacitinib citrate) OR Xeljanz OR (CP 690,550) OR CP690550 OR CP690550 OR (CP 690550) OR CP-690,550 OR ("baricitinib" [Supplementary Concept]) OR LY3009104 OR Olumiant OR INCB028050 OR ("Azathioprine"[Mesh]) OR Azothioprine OR Imurel OR Imuran OR Immuran OR ("Mycophenolic Acid"[Mesh]) OR (Mycophenolate Mofetil) OR (Mycophenolic Acid Morpholinoethyl Ester) OR Cellcept OR (Mycophenolate Sodium) OR Myfortic OR (Mycophenolate Mofetil Hydrochloride) 
medRxiv preprint doi: https://doi.org/10.1101/2020.05.01.20087494; this version posted May 6, 2020. The copyright holder for this preprint (which was not certified by peer review) is the author/funder, who has granted medRxiv a license to display the preprint in perpetuity. It is made available under a CC-BY-NC 4.0 International license .

OR (RS 61443) OR (RS-61443) OR RS61443 OR ("Cyclophosphamide"[Mesh]) OR Sendoxan OR B-518 OR (B 518) OR B518 OR Cytophosphane OR (Cyclophosphamide Monohydrate) OR Cytophosphan OR Cytoxan OR Endoxan OR Neosar OR NSC-26271 OR (NSC 26271) OR NSC26271 OR Procytox OR Cyclophosphane OR ("Cyclosporine"[Mesh]) OR Ciclosporin OR Cyclosporin OR Neoral OR (Sandimmun Neoral) OR (CyA-NOF) OR (CyA NOF) OR Sandimmune OR Sandimmun OR (CsA-Neoral) OR (CsA Neoral) OR CsANeoral OR (OL 27-400) OR (OL 27 400) OR (OL 27400) OR ("Tacrolimus"[Mesh]) OR Prograft OR FR-900506 OR (FR 900506) OR FR900506 OR (Anhydrous Tacrolimus) OR FK-506 OR (FK 506) OR FK506 OR ("Hydroxychloroquine"[Mesh]) OR (Hydroxychloroquine) OR Oxychlorochin OR Oxychloroquine OR Hydroxychlorochin OR Plaquenil OR Hidroxicloroquina OR Hydroxychloroquinum OR Oxichlorochine OR Oxicloroquine OR ("Chloroquine"[Mesh]) OR Chlorochin OR Cloroquina OR Cloroquine OR Chloroquine OR ("Antimalarials"[Mesh]) OR Antimalarials OR Anti-Malarials OR (Anti Malarials) OR Hydroquin OR Axemal OR Dolquine OR Quensyl OR Quinoric OR ("Sulfasalazine"[Mesh]) OR Salicylazosulfapyridine OR (Pyralin EN) OR Azulfadine OR Azulfidine OR Asulfidine OR (Colo-Pleon) OR (Colo Pleon) OR Pleon OR Ulcol OR Sulfasalazin OR Ucine OR Salazopyrin OR (ratio-Sulfasalazine) OR (ratio Sulfasalazine) OR ("Methotrexate"[Mesh]) OR Amethopterin OR Mexate OR ("Leflunomide"[Mesh]) OR (HWA 486) OR HWA-486 OR HWA486 OR SU101 OR Arava OR ("Dapsone"[Mesh]) OR DADPS OR Sulfonyldianiline OR Diaminodiphenylsulfone OR Diaphenylsulfone OR (4,4'-Diaminophenyl Sulfone) OR (4,4' Diaminophenyl Sulfone) OR Sulfona OR (Dapson-Fatol) OR Disulone OR Avlosulfone OR (Dapsoderm-X) OR ("Glucocorticoids"[Mesh]) OR Glucocorticoid OR ("Immunoglobulins"[Mesh]) OR Immunoglobulin OR Globulins

\#1 AND \#2 AND \#3

Filters

Publication date from 2019/11/01

The search strategy above will be used in Medline via Pubmed and will be adapted to the specifications of each database.

\section{Study selection}

Two authors will select the studies for inclusion in the review (ACPNP and FSAR). When duplicated studies are found, only one of them will be considered for inclusion. When reports using the same participants and different follow-up or outcome measurements are found, both reports will be included. However, they will be considered as parts of only one study. After removing duplicated studies and/or reports, the authors will read the study titles and abstracts. Studies that clearly do not fulfill the eligibility criteria will be excluded. The remaining studies will then be fully read and assessed for inclusion in the review. Disagreements between authors regarding the inclusion of studies will be solved by the third author (VFMT). We will present the reasons for exclusion of the studies in a flowchart. To optimize the process of screening and selection of studies, Rayyan application (8) will be used. 
medRxiv preprint doi: https://doi.org/10.1101/2020.05.01.20087494; this version posted May 6, 2020. The copyright holder for this preprint (which was not certified by peer review) is the author/funder, who has granted medRxiv a license to display the preprint in perpetuity. It is made available under a CC-BY-NC 4.0 International license.

\section{Data extraction}

Two authors (APR and FSAR) will independently extract data. Discrepancies or disagreements will be solved by a third author (VFMT). We will use a predefined form to extract data from included studies. The form will include information on: - the patients (demographic and clinical characteristics); - time points used for the assessments; - the pharmacological treatment (name of drug, treatment duration; dose); - number of patients lost to follow-up (in each group); - reasons for loss to follow-up; - approach for handling missing data (data imputation/how data imputation was performed, use of intention-to-treat approach); - sources of funding; - possibility of conflict of interests; - adverse events; outcome measures; - protocol deviations.

\section{Assessment of methodological quality in included studies and quality of the body of evidence}

We will use Risk of Bias tool (7) as recommended by Cochrane Collaboration to perform the critical appraisal of included studies; for observational studies, we will use Newcastle Ottawa Scale (9). The quality of evidence will be assessed using the Grading of Recommendations Assessment, Development and Evaluation (GRADE) (10). Assessment of risk of bias (VTC and APR), and assessment of the quality of evidence (VTC and NCJ) will be performed by two authors, and all the disagreements in the assessment of the risk of bias or quality of evidence will be solved through discussion or, if required, by consulting with a third author (ANA).

\section{Data Analysis}

We will perform analyses according to the recommendations of Cochrane, and the Cochrane Prognosis Methods Group. To perform the meta-analysis we will use R software when possible for mean difference (MD) or Hedge's/Cohen's (SMD). The package to be used is the "meta" (version 4.11-0).

We will pool mean and the standard deviation (or equivalent) for hospital admission, intensive care unit admission and/or respiratory support for adult inpatients with COVID-19 and mortality, by the inverse of variance method with random-effects model (DerSimonianLaird estimator for T2). Thus, just similar or equivalent results obtained by each primary outcome in the studies can be used. It is necessary to ensure the main assumptions to 
medRxiv preprint doi: https://doi.org/10.1101/2020.05.01.20087494; this version posted May 6, 2020. The copyright holder for this preprint (which was not certified by peer review) is the author/funder, who has granted medRxiv a license to display the preprint in perpetuity. It is made available under a CC-BY-NC 4.0 International license .

provide the correct data and to guarantee the correct interpretation. When allowed by the information of the studies results the correct statistical standardization will be provided. Aftermath, just the robust and reliable data based on equivalents primary outcomes can be used to attend the objective of this meta-analysis.

All described in the Data Extraction section for each measure must be separated according to the response categories of the interest. The data about the adverse events and clinical exams can be extracted since complete available and classified by the response as well.

\section{Dealing with missing data}

For studies that do not provide a mean and associated standard deviation (SD), we will use information and results reported in the text or tables, doing the correct inference. When the parameters established before are not available, the estimate based on other parameters will be made ensuring the correct information.

We will contact the principal investigators of the included studies asking for additional data or to clarify issues about the studies. In the absence of a reply from the authors, we will expose the data in a descriptive manner avoiding imputation.

\section{Assessment of heterogeneity}

We will employ the Cochran's $Q$ test to assess the presence of heterogeneity considering a threshold of $P$ value $<0.1$ as an indicator of whether heterogeneity is present.

In addition, we will assess statistical heterogeneity by examining the Higgins $\mathrm{I}^{2}$ statistic following these thresholds:

- <25\%: no (none) heterogeneity;

- $25 \%$ to $49 \%$ : low heterogeneity;

. $50 \%$ to $74 \%$ : moderate heterogeneity;

. $\geq 75 \%$ : high heterogeneity.

We will consider the following information for heterogeneity analysis:

Subgroup analysis

- Immune-mediated inflammatory disease (IMID) (e.g. Rheumatoid arthritis, Systemic Lupus, Spondyloarthritis, Sjögren syndrome,) 
medRxiv preprint doi: https://doi.org/10.1101/2020.05.01.20087494; this version posted May 6, 2020. The copyright holder for this preprint (which was not certified by peer review) is the author/funder, who has granted medRxiv a license to display the preprint in perpetuity. It is made available under a CC-BY-NC 4.0 International license .

- Drug treatment (number of drugs, duration of drug treatment, dose, and type of drug treatment)

- Comorbidities

- Age

- Route of administration

Sensitivity analysis

- Studies with high risk of bias

\section{Assessment of reporting biases}

When at least 10 studies are included in a meta-analysis we will explore the likelihood of reporting biases visually inspecting funnel plots. For continuous outcomes, Egger's test will be used to detect possible small study bias as recommended in Cochrane Handbook for Systematic Reviews of Interventions.

\section{DISCUSSION}

When the first reports about COVID-19 pathophysiology and clinical manifestations started to be published, there were some concerns with patients undergoing immunosuppressed treatment (3). However, unlike common viral agents, SARS-CoV-2 has not been shown to cause a more severe disease in patients with immune-mediated inflammatory diseases (5). To the best of our knowledge, the potential protective capacity of these drugs has not been properly evaluated and remains uncertain.

This rapid living review will systematically evaluate the best available evidence on the possible protective effect of drugs used in patients with immune-mediated inflammatory diseases for COVID-19. We expect it will help clinicians in their decision-making processes as, to date, no treatment has proven effective for treating COVID-19.

As we will follow the Cochrane Handbook of Systematic Reviews recommendations (7) and use extensive searches in the largest health databases, we believe we will be able to summarize the current available evidence and to clarify the potential of these drugs in preventing severe course of COVID-19. 
medRxiv preprint doi: https://doi.org/10.1101/2020.05.01.20087494; this version posted May 6, 2020. The copyright holder for this preprint (which was not certified by peer review) is the author/funder, who has granted medRxiv a license to display the preprint in perpetuity. It is made available under a CC-BY-NC 4.0 International license .

\section{REFERENCES}

1. Spinelli FR, Ceccarelli F, Di Franco M, et al. Ann Rheum Dis Epub ahead of print. doi:10.1136/annrheumdis-2020-217367

2. Favalli EG, Ingegnoli F, De Lucia O, Cincinelli G, Cimaz R, Caporali R. COVID-19 infection and rheumatoid arthritis: Faraway, so close!. Autoimmun Rev. 2020;19(5):102523. doi:10.1016/j.autrev.2020.102523

3. D'Antiga, L. Coronaviruses and immunosuppressed patients. The facts during the third epidemic. Liver Transpl. 2020; Mar. doi: 10.1002/lt.25756.

4. Hedrich, CM. COVID-19 - Considerations for the Paediatric Rheumatologist. Clin Immunol. 2020; 214: 108420. doi: 10.1016/j.clim.2020.108420.

5. Moher D, Shamseer L, Clarke M, Ghersi D, Liberati A, Petticrew M, et al. Preferred reporting items for systematic review and meta-analysis protocols (PRISMA-P) 2015 statement. Syst Rev. 2015;4:1. DOI: 10.1186/2046-4053-4-1.

6. Garritty C, Gartlehner G, Kamel C, King VJ, Nussbaumer-Streit B, Stevens A, et al. Cochrane Rapid Reviews Interim Guidance from the Cochrane Rapid Reviews Methods Group 2020. Available from: https://methods.cochrane.org/rapidreviews/sites/methods.cochrane.org.rapidreviews/files/p ublic/uploads/cochrane $\mathrm{rr}$ - guidance-23mar2020-v1.pdf.

7. Higgins J. Cochrane Handbook for Systematic Reviews of Interventions 2011.

8. Ouzzani M, Hammady H, Fedorowicz Z, Elmagarmid A. Rayyan - a web and mobile app for systematic review. Systematic Reviews. 2016; 5:210

9. Wells G, Shea B, O'Connell D, Peterson J, Welch V, Losos M et al. The NewcastleOttawa Scale (NOS) for assessing the quality of non-randomized studies in meta-analysis. https://www.ohri.ca/programs/clinical_epidemiology/oxford.asp 2014.

10.Atkins D, Best D, Briss PA, Eccles M, Falck-Ytter Y, Flottorp S, et al. Grading quality of evidence and strength of recommendations. Bmj. 2004;328(7454):1490. DOI: 10.1136/bmj.328.7454.1490. 